\title{
A Big Bang or small bangs? Effects of biotic environment on hatching
}

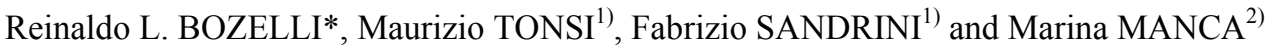 \\ Universidade Federal do Rio de Janeiro, Depto Ecologia, Lab. Limnologia, CCS - Bloco A Ilha do Fundão 21949-900 Rio de \\ Janeiro, RJ Brasil \\ ${ }^{1)}$ Universitá degli Studi di Genova, Facoltà di S.M.F.N., Gestione e Conservazione dell'Ambiente Marino, Via Balbi 5, 16126 \\ Genova, Italy \\ ${ }^{2)}$ CNR Istituto per lo Studio degli Ecosistemi, Largo V. Tonolli 50, 28922 Verbania, Italy \\ *e-mail corresponding author: bozelli@biologia.ufrj.br
}

\begin{abstract}
The beginning and end of diapause are two important transition points in cladoceran life history. The influence of environmental variables on the dynamics of these processes still deserves attention, especially as concerns the role of biotic factors. In this paper we focus on emergence from diapause, testing (1) whether ephippia of Daphnia obtusa Kurz can assess the presence in the water of typical planktivorous fish or ostracods, and (2) whether such an assessment results in changes in hatching strategy. Total number of hatchlings from D. obtusa ephippial eggs did not differ between the control and the treatments in which the presence of fish or ostracods could be detected (ANOVA, P = 0.884). However, hatching dynamics were different: most of the eggs hatched synchronously at day 4 (83.3\% of the total hatchlings number) in the control, while only a low proportion of eggs hatched on day 4 in the fish $(38.3 \%)$, and ostracod treatments $(24.0 \%$ of the total). Mean hatching time was longer, and variability larger, in the treatments than in the control; differences resulted statistically significant (ANOVA, $\mathrm{P}=0.005$ ). With respect to the control, representing a simple microcosm controlled by abiotic variables only, the treatments may be regarded as relatively complex environments, in which Daphnia is also exposed to biotic cues. Under these more complex conditions, the same number of hatchlings is obtained through different hatching dynamics. In the treatments, the first hatchlings appeared later and the hatching rate was more variable than in the control. These observations confirm previously observed patterns from laboratory experiments which tested the effect of competition and fluctuating environmental conditions (light:dark, temperature regimes) on D. obtusa reproductive and demographic parameters. They are also in agreement with recently obtained evidence concerning the importance of biotic cues for hatching of ephippial eggs. Overall, the evidence suggests that Daphnia can detect infochemicals during dormancy. Specifically, we propose that the presence in the water medium of potential predators and competitors results in a short-term hatching asynchrony of ephippial eggs.
\end{abstract}

Key words: infochemicals, gape-limited predator, resting eggs, hatching dynamic, life strategy

\section{INTRODUCTION}

To bridge periods of unsuitable physical/chemical (e.g., drought, low or high temperatures, low oxygen) or biological (e.g., poor or limited food supply, predation, competition) conditions (Brendonck \& De Meester 2003), some organisms rely on the production of socalled resting or dormant stages. Dormant stages of marine zooplankton (e.g., copepods, cladocerans, rotifers) occur in the sediments of temperate, sub-tropical and tropical bays and estuaries (Kasahara et al. 1974; Snell et al. 1983; Marazzo \& Valentin 2004). The production of diapausing eggs by freshwater zooplankton species has been well-known for more than a century (Hairston $\&$ Kearns 2002). All species of Daphnia can, at some stage in their life cycle, produce paired diapausing eggs, which are resistant to desiccation, severe changes in temperature, and digestion (Carvalho \& Wolf 1989). These eggs are enveloped in protective membranes, which include a modified part of the carapace. Together, this diapausing stage is known as an ephippium.

In addition to enabling survival during unfavorable periods, ephippia can also promote dispersal. When they are sexually produced, they allow novel clones to be introduced into the population (Carvalho \& Wolf 1989). Ephippia may thereby contribute to changes in population dynamics (Grover 1999), community structure (Wolf \& Carvalho 1989), species composition (Crispim $\&$ Watanabe 2001), and ecosystem function (Hairston, 1998). They can overlap in the sediments, forming a persistent egg bank from which females can periodically or continuously hatch (Herzig 1985), thus changing the genetic composition of the population through the overlapping of clones and generations (Harper 1977; Cáceres 1997).

The existence of egg banks indicates that not all eggs resume development immediately. This poses the question of whether this delay is a bet-hedging strategy (Slatkin 1974), or simply the result of a failure to receive the "right" cues on time, resulting in subsequent burial (Cáceres \& Tessier 2003).

If diapause is really a way for the genome to travel through time (sensu Hairston 1998) and escape from harsh conditions, it is crucial that dormant eggs should be able to detect such conditions before hatching. Entering and terminating diapause are important life history switch points, whose success is dependent on their timing (Lass et al. 2005). 
The importance of various cues as factors in inducing diapause is well-recognized (for reviews, see Dahms 1995; Ricci 2001; Brendonck \& De Meester 2003; Gyllström \& Hansson 2004).

In this paper, we will focus on emergence from diapause. As reported by Pancella \& Stross (1963), since the pioneering work of Weismann (1879), several investigators have successfully hatched resting eggs of Daphnia, and of Cladocera in general, as part of studies on sex determination. However, a careful inspection of the literature shows that the conditions prompting diapause termination are still unclear (De Stasio 1989). As more studies have been published on factors influencing the diapause process, it has become increasingly clear that ephippia can no longer be thought of as simply an over-wintering stage, produced in fall to hatch the following spring (Cáceres \& Tessier 2003). In a recent, comprehensive review, Gyllström \& Hansson (2004) observe that diapause termination in cladocerans, rotifers and copepods seems to be triggered exclusively by abiotic cues; however, studies on the role of biotic cues, such as food abundance, are scarce or non-existent, despite the fact that the idea of their potential role in freshwater zooplankton diapause development is not new (Slobodkin 1954; Hutchinson 1967; Strickler \& Twombly 1975; Hairston 1997).

It is now well known that zooplankton, like other invertebrates, are sensitive to a number of chemical compounds released into the water by other organisms and that these chemicals can act as signals of the presence and activity of food organisms, conspecifics, competitors and predators (Larsson \& Dodson 1993). Are resting stages also capable of detecting these chemicals? De Meester et al. (1998) showed that chemicals from Daphnia ephippia had no effect on the hatching rates of conspecifics. Angeler (2005) showed that Daphnia hatching success was not reduced by the presence of Gambusia at various biomass levels. On the other hand, freshwater algal species can respond to the presence or absence of grazers in the water column by regulating their recruitment rate from the sediments (Hansson 1996; Rengefors et al. 1998). The hatching of crustaceans also showed a strong negative response to the non-consumptive effects of co-occurring larval Salamandra (Blaustein 1997).

The results obtained by Lass et al. (2005) are more complicated: the response of Daphnia magna resting eggs from laboratory cultures to infochemicals released by fish appears to be clone-specific, with some clones reducing hatching success, and others increasing it or showing no response to fish of the species used in the experiments.

How can we explain the different responses observed? So far, the main factors that have been considered are abiotic cues and direct interactions, such as predation and competition. But a considerable portion of variation in the attributes of populations, communities and ecosystems (e.g., density, biomass, diversity and emergent properties) can only be understood by also paying attention to a more subtle array of supporting factors, such as the multidimensional heterogeneity of the environment. For example, chemical cues (infochemicals) can increase this heterogeneity in limnetic systems by creating refuges in time and space. Hansson (2000) calls this the "chemical network" that transfers information likely to affect predator-prey interactions and successional patterns in aquatic ecosystems.

In this paper, we assess this underlying network, testing the following hypotheses: (1) that ephippia of Daphnia obtusa Kurz from long-established egg banks in temporary pools can assess chemical information in the water from typical planktivorous fish or from directly interacting ostracods that share the same environment; and (2) that such an assessment affects hatching strategies.

\section{MATERIALS AND METHODS}

\subsection{Ephippia preparation}

Daphnia obtusa (Cladocera, Daphnidae) ephippia used in the experiments were randomly collected from the top $10 \mathrm{~cm}$ sediments of a temporary pool with no fish $(1 \mathrm{~m} \times 0.5 \mathrm{~m} \times 0.5 \mathrm{~m})$ whose Daphnia population was originally established in the mid-fifties by L.B. Slobodkin, from the culture he started to accomplish his pioneer experiments on D. obtusa population dynamics (Slobodkin 1954). The environment can be regarded as an artificial system under natural conditions (fed by meteoric waters and with no human interference).

Sediment cores were collected from several points in the pool using a Plexiglas tube (length: $1 \mathrm{~m}$; $\varnothing 6.0 \mathrm{~cm}$ ). The top $3-10 \mathrm{~cm}$ of the core were retained. Immediately after collection, samples were stored in the dark at a constant temperature of $4{ }^{\circ} \mathrm{C}$ for two months. This was intended to eliminate abiotic cues (light and temperature $>4{ }^{\circ} \mathrm{C}$ ) that might induce hatching of ephippial eggs.

After the storage period, a total of 1500 ephippia with two eggs each were isolated from the sediments. Most D. obtusa ephippia are clear, which makes it easy to identify those with 2 eggs. Isolation was carried out under a dissecting microscope (ZEISS STEMI SV11) at a magnification of $11 \times-6 \times$. After isolation, and before the beginning of the experiment, ephippia were stored in the dark at $4{ }^{\circ} \mathrm{C}$ in filtered $(0.40 \mu \mathrm{m})$ oligomineral water for a 4-week period.

\subsection{Hatching experiment}

We used twelve-well culture plates and began the experiment by randomly distributing groups of five ephippia into ten wells on each plate (maximum of 25 ephippia/well) (Tab. 1). Two wells in each plate remained empty. We used two plates for the control group and two for each treatment. Each well was filled 
with $4 \mathrm{~mL}$ of the respective medium. One third of total ephippia were placed in the control medium (same water previously used to store ephippia, filtered through $0.40 \mu \mathrm{m}$ filter); another third was given the fish treatment, and the last third the ostracod treatment. The fish treatment was obtained from ten-liter aquaria in which two specimens of a planktivorous fish (Rutilus rutilus: $5-8 \mathrm{~cm}$ body length) were kept for 24 hours at $18{ }^{\circ} \mathrm{C}$ in the same oligomineral water. The water was well oxygenated and aquaria were exposed to the same photoperiod used in the hatching of ephippia. Before use, the water was filtered through $0.40 \mu \mathrm{m}$ Nucleopore filters. The same procedure was used for the ostracod treatment. Approximately 100 ostracods were kept in 150 $\mathrm{mL}$ of water, which was renewed every 24 hours. The ostracods (Cypria ophtalmica and Heterocypris incongruens) used came from the same pool as the Daphnia. A culture was set up in the laboratory to provide the animals used in the preparation of water for the experiments every day.

Tab. 1. Design of hatching experiments of D. obtusa ephippial eggs in the various treatments and in the control. For explanation, see text.

\begin{tabular}{lccc}
\hline & Control & Fish & Ostracoda \\
\hline Ephippia/well & 25 & 25 & 25 \\
Wells/plate & 10 & 10 & 10 \\
Plates/treatment & 2 & 2 & 2 \\
Wells/treatment $=$ number of replic. & 20 & 20 & 20 \\
\hline
\end{tabular}

The medium in the wells was renewed daily. Plates were incubated in a thermostatic cell at a constant temperature of $15{ }^{\circ} \mathrm{C}$. Spring conditions were reproduced (light intensity of $2.8-3.3 \times 10^{3}$ Lux, photoperiod of $16 \mathrm{~h}$ Light: 8 h Dark).

Every 24 hours, wells were checked and hatchlings in each recorded. The experiment was continued until the $14^{\text {th }}$ day, i.e. until no hatchlings were recorded for two consecutive days.

\subsection{Statistical analysis}

We tested the statistical differences in hatching success (total number of hatchlings) and in the number of hatchlings recorded at day four (proportion of total hatchings observed) using a one-way ANOVA. Statistical differences between the treatment groups and the control group were tested in detail with a Tukey's posttest. Repeated measures of analysis of variance (RMANOVA) were tested through a Tukey's post-test on the cumulative hatchlings' values to analyze the overall hatching process. We applied the Kruskal-Wallis test and Dunnet's multiple comparison test to analyze time until hatching and statistical significance of the differences between the treatments and the control. The program GraphPad Prism version 4.03 for Windows (GraphPad Software, San Diego, California, USA, 2005) was used to perform the statistical analysis.

\section{RESULTS}

Differences in total number of hatchlings of $D . o b$ tusa ephippia between the control and the fish or ostracod treatment were not statistically significant $(P=$ $0.884, \mathrm{n}=20$ ). Values (mean $\pm \mathrm{SD}$ ) were $6.00 \pm 3.89$ in the control, $6.00 \pm 3.94$ in the fish treatment and $5.50 \pm$ 3.10 in the ostracod treatment. However, the hatching dynamics was not the same over the time frame of the experiment (Fig. 1). Repeated measures analysis of variance indicates that the overall difference is statistically significant $(F=9.50, P=0.001)$. A detailed posttest analysis of the data revealed that the difference between the control and the ostracod treatment was statistically very significant (Tukey's test, $P<0.001$ ) and that the difference between the fish and ostracod treatments was also significant (Tukey's test, $P<0.05$ ). However, the difference between the control and the fish treatment was not significant (Tukey's test, $P$ $<0.05)$.

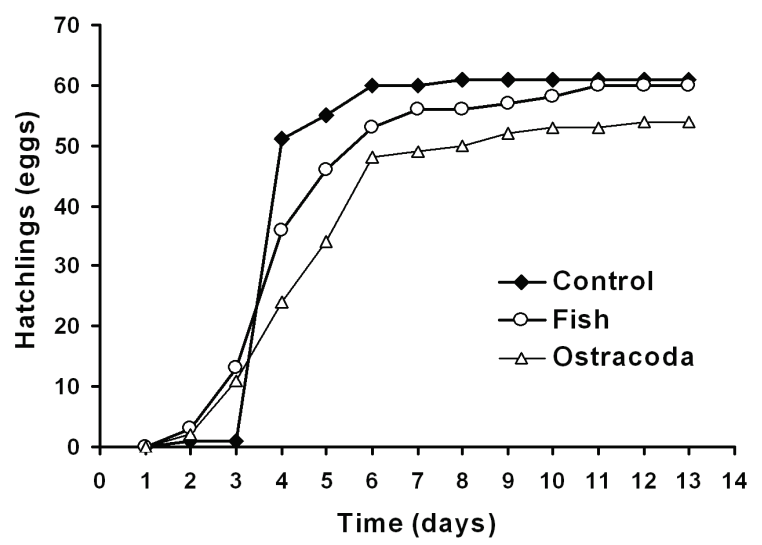

Fig. 1. Hatching success (cumulative number of hatchlings over the entire incubation period) of D. obtusa ephippial eggs in the two treatments with respect to the control.

However, hatching timing was different in the control with respect to the treatments: a very pronounced hatching peak was recorded at day 4 in the control. The mean number of hatchlings on this day was a large proportion of the total hatchlings recorded over the entire period (Fig. 2). This proportion was much lower in the two treatments. The overall difference resulted statistically highly significant $(F=15.53, P<0.0001)$. A posttest showed that differences between the control and the fish treatment and between the control and the ostracod treatment were both highly significant (both at $P$ $<0.001$; Tukey's test). In the control, $83.3 \%$ of total eggs hatched on day 4 , compared to only $38.3 \%$ in the fish treatment and $24.0 \%$ in the ostracod treatment.

Another parameter we investigated was time until hatching (Fig. 3). This parameter is somewhat comparable to developmental time of subitaneous eggs, which is among the most important vital statistics and life history traits of Daphnia (de Bernardi 1982). It is 
influenced by both abiotic and biotic environmental factors.

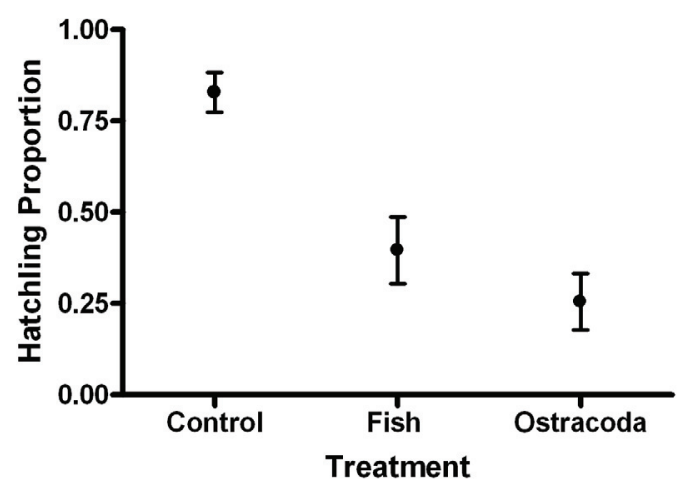

Fig. 2. Hatching proportion of D. obtusa ephippial eggs on the fourth day (\# of hatchlings at day $4 /$ total \# of hatchlings) under the different laboratory conditions tested in our experiment (values are mean $\pm \mathrm{SE}, \mathrm{n}=18$ ).

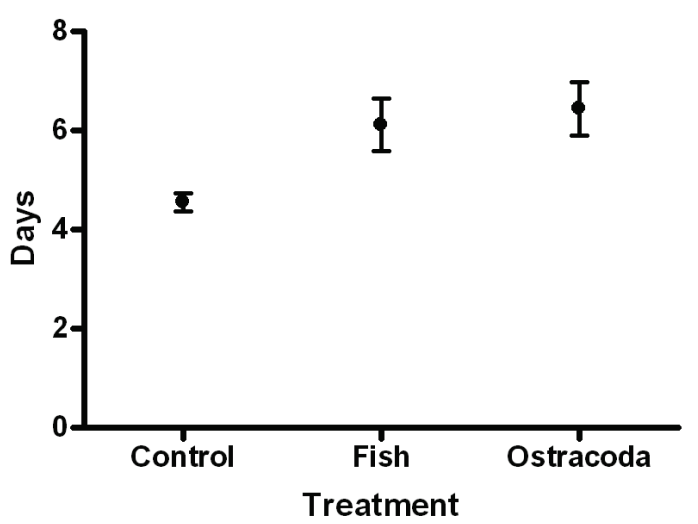

Fig. 3. Mean time until hatching of D. obtusa ephippial eggs under the laboratory conditions tested in our experiment (values are mean $\pm \mathrm{SE}, \mathrm{n}=18$ ).

Ephippia tended to delay hatching in the treatment groups (Kruskal-Wallis' test: $H(2, \mathrm{n}=18)=10.51, P=$ 0.0052 ). Variation around the mean was very low in the control compared to the two treatments. Post-hoc analysis (Dunnett's test) showed significant differences between the control group and the fish treatment, $(P$ $<0.05)$, as well as between the control group and the ostracod treatment $(P<0.01)$.

Therefore, a very similar number of hatchlings (Fig. 1) resulted from different time-specific hatchings in the control and in the treatments (Figs 2 and 3). These results suggest that the presence of other organisms in the environment affects the hatching strategy, rather than the overall hatching success, of $D$. obtusa ephippial eggs.

\section{DISCUSSION}

As aquatic environments are typically variable over time and space, organisms living in them have to face uncertainty and heterogeneity. In the small fish-free pond where $D$. obtusa ephippia were collected for our experiment, variations over time experienced by organisms include those driven by regional climate and seasonality, as well as smaller-scale variations linked to the organisms' physiological time and to interactions with other organisms sharing the same environment. Spatial heterogeneity relates to the existence of microhabitats. This is a typical situation in which the hatching of ephippial eggs is important in recruiting new individuals into the population.

In our experiment, the hatching success (i.e., the total number of hatchlings) of D. obtusa was not affected by the presence of fish or ostracod infochemicals, remaining the same irrespective of the type of organism present and its potential to interfere. Maintaining the production of offspring despite competition and food restrictions seems to be an important characteristic of D. obtusa life strategy, as observed by de Bernardi \& Manca (1982).

Our result is in agreement with Angeler (2005), who interprets a lack of response in diapause prolongation and hatching success of Daphnia in the presence of a naturally co-occurring predator (Gambusia holbrooki) as a mechanism to buffer an increase in the risk of consumptive mortality. On the other hand, Daphnia resting eggs from laboratory clones seem capable of showing a variable hatching response to the presence of fish kairomones, as a result of genetic differences (Lass et al. 2005). As observed by Angeler (2005), these contrasting results (with responses detectable at the clonal level, but undetectable in natural populations) may be due to the co-occurrence, in natural populations, of different genotypes and age-structures.

When we analyzed the hatching process, however, we found clear differences between the control group and the treatment groups. In the control, a massive hatching was detected on the fourth day: this timing agrees with the results obtained by De Meester \& De Jager (1993), who reported that more than $80 \%$ of the hatchlings of young (storage time $<5$ months) Daphnia magna ephippial eggs hatched on day 3 or 4 .

The synchronization of hatching in the control group may be interpreted as a result of laboratory conditions that mimic a simple world where organisms are mainly influenced by the abiotic environment, particularly the light:dark and temperature regimes, which in our study reproduced spring conditions.

In the two treatments, hatching was distributed over a longer period of time, implying a change in the rate of recruitment of individuals from ephippial eggs. This result is a clear indication of a change in the hatching strategy, with a transition from an "all-or-none" synchronic event into a "little by little" constant but lower recruitment and staggered hatching times.

Distributing hatching over a longer time period seems to be a response to a more complex environment, 
marked by signals of the presence of other organisms (infochemicals) actually or potentially sharing the same environment. The ostracods' signal appears to be more strongly sensed in the water by D. obtusa ephippia than the fish signal. This result can be explained by the fact that fish were not present in the pond D. obtusa ephippia were isolated from, while ostracods were.

In the more complex environment our treatments reproduce, biotic factors become important. The role of biotic factors seems to be neglected in the scientific literature on the induction (Hairston 1997) and dynamics of diapause. Delayed hatching and delayed diapause are strategies usually observed to be triggered by unfavorable climatic conditions, intense predation pressure, or reduced food resources. The delay usually occurs for a season in unpredictable, harsh environments (Alekseev \& Starobogatov 1996; Ellner et al. 1998).

Our results show a quicker response, i.e., several days sooner. Microscale time variations are not adequately demonstrated and discussed in the literature. Nilssen (1980) approached their significance as part of a study of Cyclops scutifer showing that at high food levels the larger-sized, biennial fraction of the population exhibited a "Big Bang" strategy (larger clutches released in a short time period), while the smaller-sized, annual fraction produced smaller clutches over a longer portion of their lifespan. Similarly, Chen \& Marcus (1997) interpreted delayed hatching of copepod eggs as a bet-hedging strategy meant to promote the survival of at least some offspring. By extending the hatching period of the eggs, a female may be able to increase her offspring's ability to utilize resources by exploiting temporal differences in food quality and quantity. This strategy may also reduce offspring mortality by avoiding heavy predation. We observed a smaller degree of variation, with eggs hatching over a longer period of time in order to take advantage of subtle, microscale variations.

The change observed in hatching time is basically the same strategy seen in the laboratory in D. obtusa under conditions of interspecific competition (de Bernardi \& Manca 1981): a reduction in the intrinsic rate of increase essentially results from increased age at maturity and longer development time, while offspring numbers remain constant. At the population level, delayed and non-synchronized hatching times lead to changes in age structure, similar to those observed in the laboratory under fluctuating light and temperature conditions (Manca et al. 1986) or under conditions of interspecific competition (de Bernardi \& Manca 1982).

In the simple world reproduced in our experiments by the control situation, light and temperature conditions (Stross 1966) can produce a large, synchronous explosion of life (or "Big Bang"). In the treatments, on the other hand, this simple response is modulated by information from a more complex world that is heterogeneous in many dimensions (sensu Meyers \& Bull
2002) and in which events tend to occur in a more asynchronous way ("small bangs").

D. obtusa diapausing eggs thus seem to be capable of assessing habitat quality and adjusting their hatching rate to specific environments.

Hatching asynchronously for a limited period of time makes possible the establishment of a population with a differentiated age structure. Given the relatively short life span of these organisms (mean life expectancy 45 days, maximum lifespan 90 days; de Bernardi \& Manca 1982), differences of only a few days are of critical significance. This especially applies to the period of embryo development, as the length of this period can influence age and size at maturity (Hrbáĉková 1971; de Bernardi \& Manca 1982). Hatching asynchrony is known to determine a size hierarchy among the young of altricial birds in the nest (Lack 1954), suggesting that the co-occurrence of individuals of different body sizes may present advantages in such activities as obtaining different food items.

The birth of any organism is a crucial point in its life. One is born to be alive, and reaching this point is a long, difficult process and not merely a goal. But staying alive is even more complicated and has a lot to do with the future. For all organisms, the future is uncertain (Hopper 1999), because they live in an ever-changing world (Meyers \& Bull 2002). Many organisms have adapted to living with high degrees of uncertainty (Jansen \& Stumpf 2005), and their ability to deal with this uncertainty depends on the genetic information they carry. In this sense, information means what an organism is constrained to do and what it can do or is designed for. For instance, some pathogenic bacteria have genes that can be switched off to stop the progress of infection in a host organism or prevent the recognition of the bacteria by the host's immune system (Jansen $\&$ Stumpf 2005).

When organisms exploit different habitats within an environment they are often exposed to different selection patterns for ecologically significant traits (Holt 1987). The small pond we used as a source for the Daphnia used in our experiments is fully exploited by ostracods, which were observed on several occasions interacting with $D$. obtusa, attaching to the filtering apparatus and interfering with filtering activities or grabbing the post-abdominal claws and causing damage or even the death of the animal. Green (1964) believes that although most ostracods are filter-feeders, some are predators and prey on copepods and even mysids. A reaction to the presence of ostracods was therefore largely expected.

Despite having no recent exposure to fish (the pond is fish-free), D. obtusa ephippia responded to the presence of fish infochemicals by changing their hatching strategy. This response is an example of how the information organisms carry enables them to face uncertainties in their environment. 
It appears that Daphnia diapausing eggs show different responses to particular environments, and the highest fitness results from an optimal evolutionary strategy. This consists of a complex combination of traits, including defense against biotic agents, food harvesting ability, migration, reproductive efforts and tolerance to adverse conditions, which guarantee the best long-term success (Maffei et al. 2005). A single organism can display multiple strategies, each coping with fluctuations in a different aspect of the environment (Meyers \& Bull 2002). Randomly creating phenotypic diversity - or not putting all your eggs into one basket may be all that is necessary (Jansen \& Stumpf 2005). Organisms in fluctuating environments must constantly adapt their behavior to survive. In clonal populations, this can be achieved by sensing and responding or by generating diversity through stochastic phenotype switching (Kussel \& Leibler 2005). Synchronous hatching allows no possibility for organisms to recolonize the water column within a given season, whereas continuous hatching enables populations to re-establish themselves after a mid-season crash (Cáceres \& Schwalbach 2001).

\section{CONCLUSIONS}

In conclusion, we can suggest that $D$. obtusa may be able to achieve this phenotypic diversity in an even more interesting manner, through its diapause strategies. We would like to emphasize three points that emerged from this study: (a) ephippia can assess environmental quality by sensing infochemicals; (b) they are probably also capable of detecting various levels of information; and (c) one possible response is short-term hatching asynchrony.

In a simple world, diapause terminates synchronously for subsets of the total population, and is probably triggered by environmental factors like light and temperature. However, in a more realistic variable and complex world, with potential risks and interference, diapause terminates for subsets of the total population in a longer asynchronous process, though still over a period of several days. This idea does not contradict the fact that the egg bank probably also contains some eggs with a much longer dormancy period, lasting one or more complete seasonal cycles. We justify such a strategy as a multiple anchorage in time when resting eggs hatch asynchronously for a limited time. In this way, it is possible to build up a block of individuals or subpopulations with different characteristics.

\section{ACKNOWLEDGMENTS}

We are grateful to Raymond Stross, Antonella Cattaneo and Jayme Santangelo for helpful comments on the manuscript, to Pietro Volta for providing the fish and Claudio Belis for identifying ostracods. We also acknowledge comments by Riccardo de Bernardi and language improvement by Elisa Peters. Reinaldo L. Bozelli was supported by a grant from CAPES-Brazil (BEX3129/04-7) at CNR-ISE and would like to thank the Department of Ecology of the Federal University of Rio de Janeiro for the permission to use this grant. Marina Manca and Reinaldo L. Bozelli were also supported by a CNR-CNPq cooperation project (CNPq Proc. 490954/2005-7).

\section{REFERENCES}

Alekseev, V. \& Y.I. Starobogatov. 1996. Types of diapause in Crustacea: Definitions, distribution, evolution. Hydrobiologia, 320: 15-26.

Angeler, D.G. 2005. No diapause prolongation response of Daphnia in the presence of planktivorous mosquitofish (Gambusia holbrooki). Ecological Research, 20: 619-622.

Blaustein, L. 1997. Non-consumptive effects of larval Salamandra on crustacean prey: can eggs detect predators? Oecologia, 110: 212-217.

Brendonck, L. \& L. De Meester. 2003. Egg banks in freshwater zooplankton: evolutionary and ecological archives in the sediment. Hydrobiologia, 491: 65-84

Cáceres, C. 1997. Dormancy in invertebrates. Invertebrate Biology, 116: 371-383.

Cáceres, C. \& M. S. Schwalbach. 2001. How well do laboratory experiments explain field patterns of zooplankton emergence? Freshwat. Biol., 46: 1179-1189.

Cáceres, C. \& A. J. Tessier. 2003. How long to rest: the ecology of optimal dormancy and environmental constraint. Ecology, 84: 1189-1198.

Carvalho, G. \& H.G. Wolf. 1989. Resting eggs of lakeDaphnia I. Distribution, abundance and hatching of eggs collected from various depths in lake sediments. Freshwat. Biol., 22: 459-470.

Chen, F. \& N.H. Marcus. 1997. Subitaneous, diapause, and delayed-hatching eggs of planktonic copepods from the northern Gulf of Mexico: morphology and hatching success. Mar. Biol., 127: 587-597.

Crispim, M.C. \& T. Watanabe. 2001. What can dry reservoir sediments in a semi-arid region in Brazil tell us about Cladocera? Hydrobiologia, 442: 101-105.

Dahms, H-U. 1995. Dormancy in the Copepoda - an overview. Hydrobiologia, 306: 199-211.

de Bernardi, R. \& M. Manca. 1981. Competition between Daphnia obtusa Kurz and Simocephalus vetulus (O. F. Müller): some additional experimental observations. Mem. Ist. ital. Idrobiol., 39: 31-45.

de Bernardi, R. \& M. Manca. 1982. The consequences of life history strategies on competition between two cladocerans. Mem. Ist. ital. Idrobiol., 40: 145-161.

De Meester, L. \& H. De Jager. 1993. Hatching of Daphnia sexual eggs. II. The effect of age and a second stimulus. Freshwat. Biol., 30: 227-233.

De Meester, L. C. Cousyn, \& J. Vanoverbeke. 1998. Chemical interactions, maternal effects and the hatching of Daphnia diapausing eggs. Arch. Hydrobiol. , 52: 263-272.

De Stasio, B.T. Jr. 1989. The seed bank of a freshwater crustacean: copepodology for the plant ecologist. Ecology, 70: 1377-1389.

Ellner, S.P., N.G. Jr. Hairston \& D. Babaï. 1998. Long-term diapause and spreading of risk across the life cycle. Arch. Hydrobiol., 52: 297-312.

Green, J. 1964. A biology of Crustacea. H.F. \& G. Witherby LTD, London: $122 \mathrm{pp}$.

Grover, J. 1999. Water fleas on cycles. Nature, 402: 592-593.

Gyllström, M. \& L.-A. Hansson. 2004. Dormancy in freshwater zooplankton: induction, termination and the importance of benthic-pelagic coupling. Aquatic Sci., 66: 274-295.

Hairston, N.G., Jr. 1997. Diapause as a Predator-Avoidance Adaptation. In: Kerfoot, W.C. \& Sih, A., Predation Direct 
and Indirect Impacts on Aquatic Communities. Univ. Pres of New England, Hanover: 281-290.

Hairston, N.G. Jr. 1998. Time travelers: What's timely in diapause. Arch. Hydrobiol., 52: 1-15.

Hairston, N.G., Jr. \& C.M. Kearns. 2002. Temporal dispersal: Ecological and evolutionary aspects of zooplankton egg banks and the role of sediment mixing. Integrate and Comparative Biology, 42: 481-491.

Hansson, L.-A. 1996. Behavioural response in plants: adjustment in algal recruitment induced by herbivores. Proceedings Royal Society London B, 263: 1241-1244.

Hansson, L.-A. 2000. Synergistic effects of food chain dynamics and induced behavioral responses in aquatic ecosystems. Ecology, 81: 842-851.

Harper, J.L. 1977. Population biology of plants. Academic Press, London, UK.

Herzig, A. 1985. Resting eggs - a significant stage in the life cycle of the crustaceans Leptodora kindti and Bythotrephes longimanus. Verh. int. Ver. Limnol., 22: 3088-3098.

Holt, R.D. 1987. Population dynamics and evolutionary processes the manifold roles of habitat selection. Evolutionary Ecology, 1: 331-347.

Hopper, K.R. 1999. Risk-spread and bet-hedging in insect population biology. Annual Revue Entomology, 44: 53560.

Hrbáckková, M. 1971. The size distribution of neonates and growth of Daphnia hyalina Leydig (Crustacea, Cladocera) from Lake Maggiore under laboratory conditions. Mem. Ist. ital. Idrobiol., 27: 357-367.

Hutchinson, G.E. 1967. A treatise on limnology, v. 2, John Wiley, New York: 1115 pp.

Jansen, V.A.A. \& M.P.H. Stumpf. 2005. Making sense of evolution in an uncertain world. Science, 309: 2005-2007.

Kasahara, S., S. Uye \& T. Onbé. 1974. Calanoid copepod eggs in sea-bottom muds. Mar. Biol., 31: 25-29

Kussel, E. \& S. Leibler. 2005. Phenotypic diversity, population growth, and information in fluctuating environments. Science, 309: 2075-2077.

Lack, D. 1954. The natural regulation of animal numbers. Oxford Univ. Press, Oxford: $460 \mathrm{pp}$.

Larsson, P. \& S. Dodson. 1993. Chemical communication in planktonic animals. Arch. Hydrobiol., 129: 129-155.

Lass, S., M. Vos, J. Wolinska \& P. Spaak. 2005. Hatching with the enemy: Daphnia diapausing eggs hatch in the presence of fish kairomones. Chemoecology, 15: 7-12.

Manca, M. \& R. de Bernardi. 1987. Feeding and energy budget estimation in Daphnia obtusa. Hydrobiologia, 145: 269-274

Received: April 2008

Accepted: July 2008
Manca, M., R. de Bernardi \& A. Savia. 1986. Effects of fluctuating temperature and light conditions on population dynamics and life strategies of migrating and migrating Daphnia species. Mem. Ist. ital. Idrobiol., 44: 177-202.

Marazzo, A. \& J.L. Valentin. 2004. Reproductive aspects of marine cladocerans Penilia avirostris and Pseudevadne tergestina (Crustacea, Branchiopoda) in the outer part of Guanabara Bay, Brazil. Brazilian Journal of Biology, 64: 543-549.

Maffei, C., D. Vagaggini, P. Zarattini \& G. Mura. 2005. The dormancy problem for Crustacea Anostraca: A rigorous model connecting hatching strategies and environmental conditions. Ecological Modelling, 185: 469-481.

Meyers, S.A. \& J.J. Bull. 2002. Fighting change with change: adaptive variation in an uncertain world. Trends in Ecology and Evolution, 17: 551-557.

Nilssen, J.P. 1980. When and how to reproduce: a dilemma for limnetic cyclopoid copepods. In: W.C. Kerfoot (Ed.), Evolution and ecology of zooplankton communities. Univ. Press of New England: 418-426.

Pancella, J.R. \& R.G. Stross. 1963. Light induced hatching of Daphnia resting eggs. Chesapeake Science, 4: 135-140.

Rengefors, K., I. Karlsson \& L.-A Hansson. 1998. Algal cyst dormancy: a temporal escape from herbivory. Proceedings Royal Society London. B, 265: 1353-1358.

Ricci, C. 2001. Dormancy patterns in rotifers. Hydrobiologia, 446/447: 1-11.

Slatkin, M. 1974. Hedging one's evolutionary bets. Nature, 250: 704-705.

Slobodkin, L.B. 1954. Population dynamics in Daphnia obtusa Kurz. Ecological Monographs, 24: 69-88.

Snell, T.W., B.E. Burke \& S.D. Messur. 1983. Size and distribution of resting eggs in a natural population of the rotifer Brachionus plicatilis. Gulf Research Report, 7: 285287.

Strickler, J.R. \& S. Twombly. 1975. Reynolds number, diapause and predatory copepods. Verh. int. Ver. Limnol., 19: 2943-2950.

Stross, R.G. 1966. Light and temperature requirements for diapause development and release in Daphnia. Ecology, 47: $368-374$.

Weismann, A. 1879. Beiträge zue Naturgeschichte der Daphnoiden. Zeitschrift Zoologie, 33: 55.

Wolf, H.G. \& G. Carvalho. 1989. Resting eggs of lake-Daphnia II. In situ observations on the hatching of eggs and their contribution to population and community structure. Freshwat. Biol., 22: 471-478 